\title{
Photochemical Heck Benzylation of Styrenes Catalyzed by $\mathrm{Na}\left[\mathrm{FeCp}(\mathrm{CO})_{2}\right]$
}

\author{
Greyson W. Waldhart and Neal P. Mankad* \\ Department of Chemistry, University of Illinois at Chicago, 845 West Taylor Street, Chicago, IL \\ 60607, USA \\ *Corresponding author: npm@uic.edu, 1-312-355-4990
Keywords: Iron catalysis; Heck coupling; Photochemistry; Carbon-carbon coupling; $C$-H functionalization; Base metal catalysis \\ This paper is dedicated in memory of A.E. Shilov and his inspiring contributions to \\ organometallic chemistry

\begin{abstract}
Iron-catalyzed Heck coupling of benzyl chlorides and styrenes proceeds under photochemical conditions using the well-known anionic complex, $\left[\mathrm{FeCp}(\mathrm{CO})_{2}\right]^{-}\left(\mathrm{Fp}^{-}\right)$, as a catalyst. The reaction likely proceeds through the established $\mathrm{S}_{\mathrm{N}} 2$ mechanism for Fp ${ }^{-}$alkylation, followed by styrene migratory insertion and $\beta$-hydride elimination steps that are enabled by photochemical CO dissociation.
\end{abstract}

\section{Introduction}

The ability to catalyze transformations of $\mathrm{C}-\mathrm{H}$ bonds to $\mathrm{C}-\mathrm{C}$ and $\mathrm{C}-\mathrm{X}$ bonds has revolutionized synthesis [1-6]. Of the various available technologies, the Mizoroki-Heck reaction ("Heck reaction") is among the most prolific in its utility for converting $\mathrm{C}-\mathrm{H}$ bonds to $\mathrm{C}-\mathrm{C}$ bonds within complex organic structures [7]. While Pd catalysts are ubiquitous for Heck arylations of alkenes, Pd-catalyzed Heck alkylations are less common and have limited scope. Alkyl halides pose several challenges as coupling partners in traditional Pd catalysis: slow oxidative addition at $\operatorname{Pd}(0)$ [8,9], slow alkene insertion into $\mathrm{Pd}(\mathrm{II})$-alkyls [10], and unproductive $\beta$-hydride elimination suppress productive alkene alkylation. For these reasons, Heck-type alkylation of alkenes is an open problem in $\mathrm{Pd}$ catalysis [8-17] and presents an opportunity for contributions from alternative metals. Catalysts based on Ti [18], Co [19,20], and Ni [21,22] have proven successful in this area, often requiring reactive co-reagents such as Grignards or silyl triflates to provide a greater driving force. A photocatalytic approach to this problem also has been demonstrated [23]. The field of Fe-catalyzed coupling reactions is increasingly prolific [24-26] and has established the ability to engage alkyl halide substrates as coupling partners [27-32]. In this report, we disclose an Fe-catalyzed intermolecular Heck benzylation of styrenes under photochemical conditions using the well-known anionic complex, $\left[\mathrm{FeCp}(\mathrm{CO})_{2}\right]^{-}\left(\mathrm{Fp}^{-}\right)$.

\section{Results and Discussion}

Recently, Yasuda et al. disclosed the stoichiometric arylation of styrenes by Fp-Ar reagents at high temperatures (Figure 1a) [33]. In principle, this transformation could serve as the basis for a closed catalytic cycle for Heck coupling (Figure 1b) if only the aryliron(II) bond could be installed by activation of an $\mathrm{Ar}-\mathrm{X}$ reagent by $\mathrm{Fp}^{-}$. In practice, this is not possible because the $\mathrm{S}_{\mathrm{N}} 2$ pathway [34,35] for oxidative addition by $\mathrm{Fp}^{-}$is not compatible with aryl halides. Indeed, arylation of $\mathrm{Fp}^{-}$is itself known to require $\mathrm{Pd}$ catalysis [36]. Accordingly, 
attempts at either stoichiometric reactions of aryl halides with $\mathrm{Fp}^{-}$or catalytic arylation of styrene using $\mathrm{Fp}^{-}$did not result in detectable conversion in our hands.
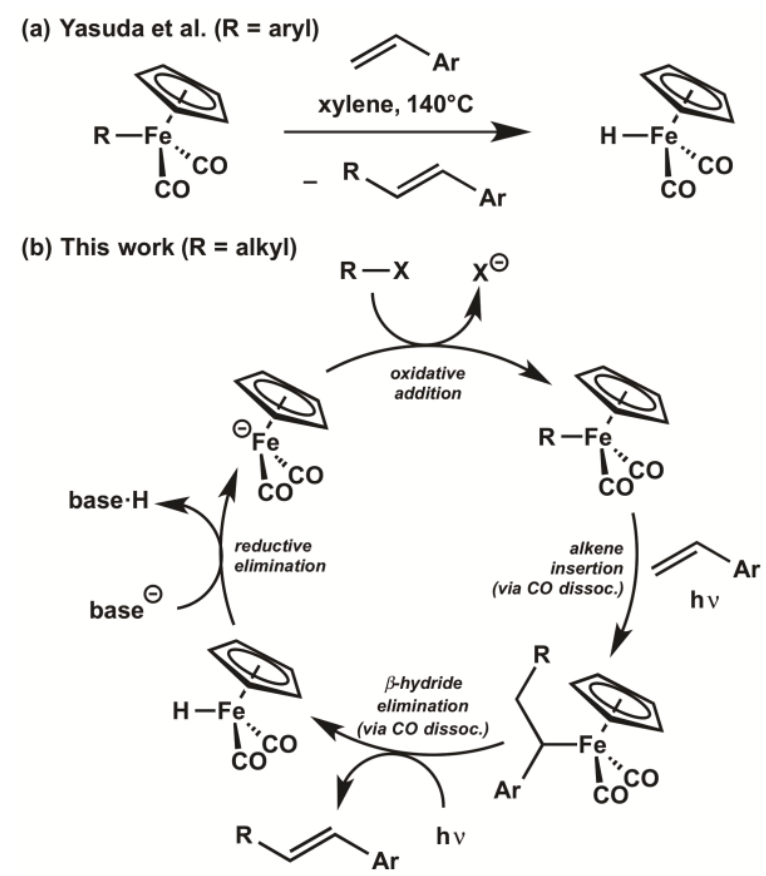

Figure 1. (a) Stoichiometric Fe-mediated Heck arylation; (b) Fe-catalyzed Heck alkylation. The steps of the catalytic cycle thought to require photochemical CO dissociation are marked.

On the other hand, $\mathrm{Fp}^{-}$is known to active alkyl halides readily [37-39], and so we shifted our focus to catalytic alkylation of styrene using $\mathrm{Fp}^{-}$. Despite the long history of organoiron chemistry using the Fp fragment [37-39], such catalysis has not been reported previously. As an initial test reaction, we examined the catalytic coupling of benzyl chloride and styrene, producing C-C coupling product 1 (Table 1). We initially used air-stable $\mathrm{FpCH}_{2} \mathrm{Ph}$ as a catalyst and pursued photochemical conditions due to the instability of some of the hypothetical catalytic intermediates at high temperatures. A series of tests indicated catalytic turnover was indeed possible, with di- $n$-butyl ether being the optimal solvent and $\mathrm{NaO} t \mathrm{Bu}$ the optimal base under UV irradiation with a 450-W medium-pressure $\mathrm{Hg}$ arc lamp (see Supplementary Data for optimization details). Addition of excess amounts of either benzyl chloride (Table 1, Entry 2) or $\mathrm{NaO} t \mathrm{Bu}$ (Table 1, Entry 6) decreased conversion to 1. Excess styrene increased conversion (Table 1, Entries 3-4), presumably because rapid interception of the $\mathrm{FpCH}_{2} \mathrm{Ph}$ intermediate by styrene is necessary to outcompete side reactions such as the well-known 1,1-migratory insertion of $\mathrm{CO}$ [39]. However, a small inhibitory effect was observed at high styrene loadings (Table 1, Entry 5). The optimal ratio of benzyl chloride ( 1 equiv), styrene (6 equiv), $\mathrm{NaO} t \mathrm{Bu}$ (1.5 equiv), and $\mathrm{FpCH}_{2} \mathrm{Ph}(0.25$ equiv) produced 1 in $89 \%$ conversion and was used for subsequent studies (Table 1, Entry 9). No conversion to 1 was observed under these conditions when the $\mathrm{Fe}$ complex was omitted or when $\mathrm{Pd}(\mathrm{OAc})_{2}$ or $\mathrm{Pd}\left(\mathrm{PPh}_{3}\right)_{2} \mathrm{Cl}_{2}$ were used as catalysts in place of the Fe complex. Under the optimized conditions, the $E: Z$ ratio for 1 was $>9.5: 1$. Use of NaFp in place of $\mathrm{FpCH}_{2} \mathrm{Ph}$ resulted in only a slight decrease in conversion to $\mathbf{1}$, and so $\mathrm{NaFp}$ was used as the catalyst in subsequent studies. Other, less nucleophilic [38], metal carbonyl anions such as $\mathrm{Mn}(\mathrm{CO})_{5}{ }^{-}$and $\mathrm{MCp}(\mathrm{CO})_{3}{ }^{-}(\mathrm{M}=\mathrm{Cr}, \mathrm{Mo}, \mathrm{W})$ did not produce 1 under these conditions. 
Table 1. Optimization of reaction stoichiometry ${ }^{a}$

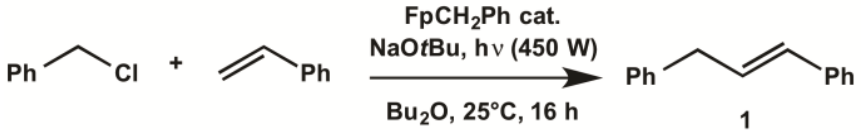

\begin{tabular}{|c|c|c|c|c|c|}
\hline Entry & $\mathrm{PhCH}_{2} \mathrm{Cl}$ (equiv) & Styrene (equiv) & $\mathrm{NaOt} \mathrm{Bu}$ (equiv) & $\mathrm{FpCH}_{2} \mathrm{Ph}$ (equiv) & ${\text { Yield of } \mathbf{1}^{b}}^{b}$ \\
\hline 1 & 1 & 1 & 1 & 0.1 & $34 \%$ \\
\hline 2 & 2 & 1 & 1 & 0.1 & $23 \%$ \\
\hline 3 & 1 & 2 & 1 & 0.1 & $53 \%$ \\
\hline 4 & 1 & 6 & 1 & 0.1 & $72 \%$ \\
\hline 5 & 1 & 10 & 1 & 0.1 & $62 \%$ \\
\hline 6 & 1 & 1 & 2 & 0.1 & $24 \%$ \\
\hline 7 & 1 & 1 & 1 & 0.05 & $4 \%$ \\
\hline 8 & 1 & 1 & 1 & 0.25 & $35 \%$ \\
\hline 9 & 1 & 6 & 1.5 & 0.25 & $89 \%$ \\
\hline 10 & 1 & 6 & 1.5 & 0.2 & $63 \%$ \\
\hline 11 & 1 & 6 & 1.5 & 0 & $0 \%$ \\
\hline
\end{tabular}

${ }^{a}$ Selected data; full optimization in Supplementary Data. ${ }^{b}$ Determined by ${ }^{1} \mathrm{H}$ NMR integration relative to an internal standard.

Several substituted benzyl chloride reagents were examined using styrene as a coupling partner. In addition to the major Heck coupling product (2), a minor product (3) resulting from alkene migration was observed in most cases (Table 2). The two isomers were not separable by standard column chromatography techniques in the selected cases we attempted to purify, and so NMR yields are presented here. In all cases, the corresponding $Z$-alkene isomers either were not observed or were observed in trace $(<1 \%)$ amounts. Catalytic results were similar in the presence of several different para substitutents (Table 2, Entries 1-8). The $\mathrm{C}\left(s p^{3}\right)$-Cl bond of $p$ chlorobenzyl chloride is activated selectively over the $\mathrm{C}\left(s p^{2}\right)-\mathrm{Cl}$ bond (Table 2, Entry 8) due to the $\mathrm{S}_{\mathrm{N}} 2$-like nature of oxidative addition. On the other hand, Pd catalysts would active both positions unselectively, and we have been unable to identify previous examples of $p$ chlorobenzyl chloride engaging in Pd-catalyzed cross coupling of any sort. Such catalytic selectivity orthogonal to $\mathrm{Pd}$ has been observed with other non-traditional elements [19$23,28,29,31]$. Coordinating groups in the para position such as $\mathrm{CN}, \mathrm{SMe}$, and $\mathrm{CO}_{2} \mathrm{Me}$ prevented catalytic turnover (Table 2, Entries 10-12). Sterically hindered ortho-methylbenzyl chloride also did not submit to efficient catalysis (Table 2, Entry 13), although $\alpha$-methylbenzyl chloride performed reasonably well (Table 2, Entry 14) compared to other less hindered substrates. Benzyl fluoride (0\%), benzyl bromide (11\%), cyclohexyl chloride (0\%), and neo-pentyl chloride $(0 \%)$ all performed much worse than benzyl chloride itself. Benzyl tosylate reacted with the base under these conditions to form $\mathrm{PhCH}_{2} \mathrm{O} t \mathrm{Bu}$. 
Table 2. Scope in benzyl chloride

\begin{tabular}{|c|c|c|c|c|}
\hline Entry & $\mathrm{R}$ & $\mathrm{R}^{\prime}$ & Total Yield of $\mathbf{2}$ and $\mathbf{3}^{a}$ & Ratio $2: 3^{a}$ \\
\hline 1 & $\mathrm{H}$ & $\mathrm{H}$ & $89 \%$ & -- \\
\hline 2 & $p$-Me & $\mathrm{H}$ & $48 \%$ & $3.4: 1$ \\
\hline 3 & $p$-OMe & $\mathrm{H}$ & $52 \%$ & $1: 0$ \\
\hline 4 & $p-\mathrm{Ph}$ & $\mathrm{H}$ & $51 \%$ & $1: 0$ \\
\hline 5 & $p-\mathrm{CHCH}_{2}$ & $\mathrm{H}$ & $44 \%$ & n.d. ${ }^{b}$ \\
\hline 6 & $p-\mathrm{CF}_{3}$ & $\mathrm{H}$ & $92 \%$ & $1.2: 1$ \\
\hline 7 & $p-\mathrm{F}$ & $\mathrm{H}$ & $50 \%$ & $2.3: 1$ \\
\hline 8 & $p-\mathrm{Cl}$ & $\mathrm{H}$ & $50 \%$ & $2.1: 1$ \\
\hline 9 & $p-\mathrm{Br}$ & $\mathrm{H}$ & $26 \%$ & $2.5: 1$ \\
\hline 10 & $p$-CN & $\mathrm{H}$ & $0 \%$ & -- \\
\hline 11 & $p$-SMe & $\mathrm{H}$ & $20 \%$ & 3.6:1 \\
\hline 12 & $p-\mathrm{CO}_{2} \mathrm{Me}$ & $\mathrm{H}$ & $28 \%$ & n.d. ${ }^{b}$ \\
\hline 13 & $o$-Me & $\mathrm{H}$ & $34 \%$ & $3.2: 1$ \\
\hline 14 & $\mathrm{H}$ & $\mathrm{Me}$ & $42 \%$ & $1: 0$ \\
\hline
\end{tabular}

${ }^{a}$ Determined by ${ }^{1} \mathrm{H}$ NMR integration relative to an internal standard. ${ }^{b}$ Not determined due to peak overlap.

Similar experiments were carried out with substituted styrenes using benzyl chloride as a coupling partner. Although $p$-methylstyrene performed equally well as styrene itself (Table 3, Entries 1-2), other para substituents were not well tolerated (Table 3, Entries 3-6). Here, once again, aryl-halide linkages were tolerated and remained intact under these conditions (Table 3, Entry 7): product 4 produced from $p$-bromostyrene has not been constructed by Heck coupling before, to our knowledge. Less activated alkenes such as vinyltrimethylsilane, $t$-butylethylene, and cyclopentene did not undergo coupling under these conditions. 
Table 3. Scope in styrene

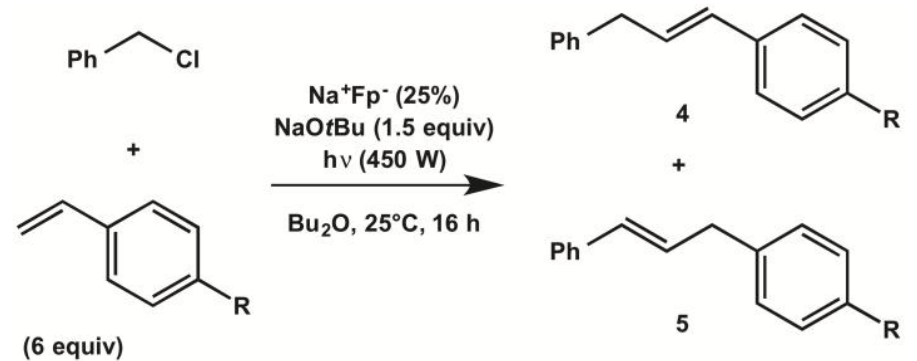

\begin{tabular}{|c|c|c|c|}
\hline Entry & $\mathrm{R}$ & Total Yield of $\mathbf{4}$ and $\mathbf{5}^{a}$ & Ratio $4: 5^{a}$ \\
\hline 1 & $\mathrm{H}$ & $89 \%$ & -- \\
\hline 2 & $\mathrm{Me}$ & $88 \%$ & 2.4:1 \\
\hline 3 & $\mathrm{OMe}$ & $26 \%$ & $2.2: 1$ \\
\hline 4 & $\mathrm{Ph}$ & $0 \%$ & -- \\
\hline 5 & $\mathrm{~F}$ & $34 \%$ & $1.7: 1$ \\
\hline 6 & $\mathrm{Cl}$ & $31 \%$ & $1.2: 1$ \\
\hline 7 & $\mathrm{Br}$ & $45 \%$ & $1: 0$ \\
\hline
\end{tabular}

${ }^{a}$ Determined by ${ }^{1} \mathrm{H}$ NMR integration relative to an internal standard.

Coupling reactions of disubstituted styrenes with benzyl chloride also were examined (Figure 2). No conversion to products was observed with $\alpha$-methylstyrene, and only trace conversion was observed with cis- $\beta$-methylstyrene. However, exemplary results were obtained with trans- $\beta$-methylstyrene ( $83 \%$ ).<smiles>C=C(C)c1ccccc1</smiles>

$0 \%$<smiles>C/C=C\c1ccccc1</smiles>

$12 \%$<smiles>C/C=C/c1ccccc1</smiles>

$83 \%$

Figure 2. Catalytic results for the coupling of disubstituted styrenes shown with benzyl chloride. Reaction conditions were as in Tables 2-3. Yields were determined by ${ }^{1} \mathrm{H}$ NMR integration relative to an internal standard.

Regarding the mechanism of catalysis, we favor a classical Heck-type mechanism (Figure $1 b$ ) in which the role of the UV light is to induce $\mathrm{CO}$ dissociation and reveal unsaturated intermediates necessary for insertion/elimination processes. This proposal stands opposed to a radical mechanism in which the role of the UV light would be to induce Fe-R homolysis, followed by R t trapping by the styrene [40]. In related half-sandwich metal carbonyl complexes, ultrafast infrared studies have established that UV irradiation induces CO dissociation to yield unsaturated intermediates with $\mu$ s lifetimes sufficiently long to coordinate exogenous ligands (here, the styrene), [41] and similar conclusions were reached for the photochemistry of $\mathrm{FpBR}_{2}$ complexes [42-45]. Alkylation of $\mathrm{Fp}^{-}$is known to proceed through a two-electron, $\mathrm{S}_{\mathrm{N}} 2$ pathway [34,35]. Furthermore, a mechanism involving benzyl radical transfer would be unlikely to discriminate to such a large extent between the cis- and trans- $\beta$-methylstyrene isomers (Figure 2 ). We also note that the coupling of benzyl chloride and styrene was inhibited by the presence of either CO (1 atm, 25\% conversion) or pyridine ( 0.5 equiv, $45 \%$ conversion; 6.0 equiv, $30 \%$ conversion), consistent with $\mathrm{CO}$ dissociation being involved in the catalytic pathway. Although 
conversion was affected adversely by radical traps such as 1,4-cyclohexadiene (1 equiv, $62 \%$ conversion) and 9,10-dihydroanthracene (1 equiv, 30\% conversion), this inhibition is consistent with any pathway proceeding through $\mathrm{FpH}$ due to its instability towards $\mathrm{H}$-atom donors [46]. Nonetheless, Fe-R homolysis may represent an unproductive pathway competing with productive Heck coupling in this system. For example, when analyzing the crude reaction mixture from one of the low-yielding catalytic reactions (Table 2, Entry 2), we found that all of the benzyl chloride substrate had been consumed even though the corresponding bibenzyl was not detected and the Heck coupling product was formed in only $48 \%$ yield. These observations indicate that some of the unaccounted mass balance results from non-productive decomposition of the benzyl chloride partner under these conditions, possibly through formation and subsequent decomposition of the benzyl radical.

\section{Conclusions}

In conclusion, the first Fe-catalyzed Heck alkylation of alkenes is reported here. The method is not of preparative use at this time due to modest yields and alkene isomerization, and studies towards overcoming these obstacles are underway in our laboratory. Nonetheless, these initial results highlight a promising strategy for developing methods that convert $\mathrm{C}-\mathrm{H}$ bonds to C-C bonds using earth-abundant metal catalysts.

\section{Experimental Section}

General Considerations. Unless otherwise specified, all reactions and manipulations were performed under purified $\mathrm{N}_{2}$ in an MBraun glovebox or using standard Schlenk techniques. Glassware was oven-dried prior to use. Tetrahydrofuran, toluene, pentane, diethyl ether, acetonitrile, methylene chloride, heptane, dioxane and triethylamine were sparged with argon and dried using a Glass Contour Solvent System built by Pure Process Technology, LLC. Acetone, hexanes, methanol and ethanol were purified by distillation according to standard procedures. All other solvents were purified by repeated freeze-pump-thaw cycles followed by prolonged storage over activated, $3-\AA$ molecular sieves. Photolysis was conducted using a $450 \mathrm{~W}$ Hanovia mercury arc lamp in an immersion well filled with circulating water, and samples were placed approximately 0.75 inches from the lamp. NMR spectra were recorded at ambient temperature using Bruker Avance DPX-400, Bruker Avance DRX-500 and Bruker Avance-II $800 \mathrm{MHz}$ spectrometers with a delay time of $5 \mathrm{~s}$ and a pulse time of $3.0 \mu \mathrm{s} .{ }^{1} \mathrm{H}$ NMR chemical shifts and integration values were referenced to an internal standard (mesitylene). $\mathrm{Na}\left[\mathrm{Fe}(\mathrm{CO})_{2}\left(\eta^{5}-\mathrm{C}_{5} \mathrm{H}_{5}\right)\right][46], \mathrm{K}\left[\mathrm{Fe}(\mathrm{CO})_{2}\left(\eta^{5}-\mathrm{C}_{5} \mathrm{H}_{5}\right)\right]$ [47], [ $\left.\mathrm{Fe}\left(\mathrm{CH}_{2} \mathrm{C}_{6} \mathrm{H}_{5}\right)(\mathrm{CO})_{2}\left(\eta^{5}-\mathrm{C}_{5} \mathrm{H}_{5}\right)\right]$ [48], and benzyl fluoride [49], were prepared using a literature procedures. Unless otherwise indicated, all other chemicals were purchased from commercial sources and used without further purification.

General procedure for catalytic reactions. In a nitrogen filled glovebox, catalyst $(\sim 10$ $\mathrm{mg}$ ) was dissolved in solvent $(1 \mathrm{~mL})$. Base, benzyl chloride, and styrene were added to the solution according the stoichiometry described in the data tables or in the text, and then the reaction solution was quantitatively transferred to either a J-Young NMR tube or an airtight NMR tube with screw cap seal. The NMR tube was taken out of the glovebox and placed approximately 0.75 inches away from the condenser of a $450 \mathrm{~W}$ mercury arc UV lamp. After 16 hours, the NMR tube was transferred back into the glovebox, and the reaction mixture was filtered through a small plug of silica gel. Multiple aliquots of diethyl ether were used to wash the silica gel plug. Volatiles were removed under vacuum until an oil or solid remained. This residue was dissolved in $\mathrm{CDCl}_{3}$, and mesitylene was added as an internal standard. Yields and 
isomeric ratios were determined by integrating the ${ }^{1} \mathrm{H}$ NMR resonance for the benzylic protons of the product(s) relative to the internal standard. In the ${ }^{1} \mathrm{H}$ NMR spectra shown as Supplementary Data for the product mixtures, the chemical shifts and integral values for the benzylic protons and the internal standard peaks are shown. Yields are reported as averages of three independent runs.

\section{Acknowledgements}

Funding was provided by the UIC Department of Chemistry (start-up funds), the UIC Campus Research Board (Pilot Grant), and the NSF (CHE-1362294). Dr. Benjamin Ramirez assisted with NMR spectroscopy.

\section{References}

[1] A.E. Shilov, A.A. Shteinman, Coord. Chem. Rev. 24 (1977) 97.

[2] R.H. Crabtree, J. Chem. Soc., Dalton Trans. (2001) 2437.

[3] J.A. Labinger, J.E. Bercaw, Nature 417 (2002) 507.

[4] I.A.I. Mkhalid, J.H. Barnard, T.B. Marder, J.M. Murphy, J.F. Hartwig, Chem. Rev. 110 (2010) 890.

[5] W.R. Gutekunst, P.S. Baran, Chem. Soc. Rev. 40 (2011) 1976.

[6] H.M.L. Davies, J. Du Bois, J.-Q. Yu, Chem. Soc. Rev. 40 (2011) 1855.

[7] A.B. Dounay, L.E. Overman, Chem. Rev. 103 (2003) 2945.

[8] Z. Yang, J.S. Zhou, J. Am. Chem. Soc. 134 (2012) 11833.

[9] H. Narahashi, A. Yamamoto, I. Shimizu, Chem. Lett. 33 (2004) 348.

[10] H. Narahashi, I. Shimizu, A. Yamamoto, J. Organomet. Chem. 693 (2008) 283.

[11] Y. Zou, J.S. Zhou, Chem. Commun. 50 (2014) 3725.

[12] K.S. Bloome, R.L. McMahen, E.J. Alexanian, J. Am. Chem. Soc. 133 (2011) 20146.

[13] L. Firmansjah, G.C. Fu, J. Am. Chem. Soc. 129 (2007) 11340.

[14] L. Wang, Y. Pan, X. Jiang, H. Hu, Tet. Lett. 41 (2000) 725.

[15] P. Yi, Z. Zhuangyu, H. Hongwen, Synth. Commun. 22 (1992) 2019.

[16] P. Yi, Z. Zhuangyu, H. Hongwen, Synthesis 1995 (1995) 245.

[17] K. Higuchi, K. Sawada, H. Nambu, T. Shogaki, Y. Kita, Org. Lett. 5 (2003) 3703.

[18] J. Terao, H. Watabe, M. Miyamoto, N. Kambe, Bull. Chem. Soc. Jpn. 76 (2003) 2209.

[19] Y. Ikeda, T. Nakamura, H. Yorimitsu, K. Oshima, J. Am. Chem. Soc. 124 (2002) 6514.

[20] M.E. Weiss, L.M. Kreis, A. Lauber, E.M. Carreira, Angew. Chem. Int. Ed. 50 (2011) 11125 .

[21] E.A. Standley, T.F. Jamison, J. Am. Chem. Soc. 135 (2013) 1585.

[22] R. Matsubara, A.C. Gutierrez, T.F. Jamison, J. Am. Chem. Soc. 133 (2011) 19020.

[23] Q. Liu, H. Yi, J. Liu, Y. Yang, X. Zhang, Z. Zeng, A. Lei, Chem. Eur. J. 19 (2013) 5120.

[24] C.-L. Sun, B.-J. Li, Z.-J. Shi, Chem. Rev. 111 (2011) 1293.

[25] B.D. Sherry, A. Fürstner, Acc. Chem. Res. 41 (2008) 1500.

[26] C. Bolm, J. Legros, J. Le Paih, L. Zani, Chem. Rev. 104 (2004) 6217.

[27] R.B. Bedford, P.B. Brenner, E. Carter, T. Gallagher, D.M. Murphy, D.R. Pye, Organometallics 33 (2014) 5940. 
[28] R.B. Bedford, M. Huwe, M.C. Wilkinson, Chem. Commun. (2009) 600.

[29] R.B. Bedford, M.A. Hall, G.R. Hodges, M. Huwe, M.C. Wilkinson, Chem. Commun. (2009) 6430.

[30] T.C. Atack, R.M. Lecker, S.P. Cook, J. Am. Chem. Soc. 136 (2014) 9521.

[31] M. Nakamura, K. Matsuo, S. Ito, E. Nakamura, J. Am. Chem. Soc. 126 (2004) 3686.

[32] T. Nagano, T. Hayashi, Org. Lett. 6 (2004) 1297.

[33] S. Yasuda, H. Yorimitsu, K. Oshima, Organometallics 29 (2010) 2634.

[34] G.M. Whitesides, D.J. Boschetto, J. Am. Chem. Soc. 91 (1969) 4313.

[35] P.J. Krusic, P.J. Fagan, J. Am. Chem. Soc. 99 (1977) 250.

[36] S. Yasuda, H. Yorimitsu, K. Oshima, Organometallics 27 (2008) 4025.

[37] T.S. Piper, G. Wilkinson, J. Inorg. Nucl. Chem. 3 (1956) 104.

[38] R.B. King, Acc. Chem. Res. 3 (1970) 417.

[39] R. Theys, M. Dudley, M. Hossain, Coord. Chem. Rev. 253 (2009) 180.

[40] B. Giese, G. Thoma, Helv. Chim. Acta 74 (1991) 1143.

[41] J.P. Lomont, S.C. Nguyen, C.B. Harris, Acc. Chem. Res. 47 (2014) 1634.

[42] K.M. Waltz, C.N. Muhoro, J.F. Hartwig, Organometallics 18 (1999) 3383.

[43] K.M. Waltz, J.F. Hartwig, J. Am. Chem. Soc. 122 (2000) 11358.

[44] K.M. Waltz, X. He, C. Muhoro, J.F. Hartwig, J. Am. Chem. Soc. 117 (1995) 11357.

[45] K.M. Waltz, J.F. Hartwig, Science 277 (1997) 211.

[46] T.A. Shackleton, M.C. Baird, Organometallics 8 (1989) 2225.

[47] T. Ohishi, Y. Shiotani, M. Yamashita, J. Org. Chem. 59 (1994) 250.

[48] J.P. Bibler, A. Wojcicki, J. Am. Chem. Soc. 88 (1966) 4862.

[49] J.C.T. Leung, C. Chatalova-Sazepin, J.G. West, M. Rueda-Becerril, J.-F. Paquin, G.M. Sammis, Angew. Chem. Int. Ed. 51 (2012) 10804. 

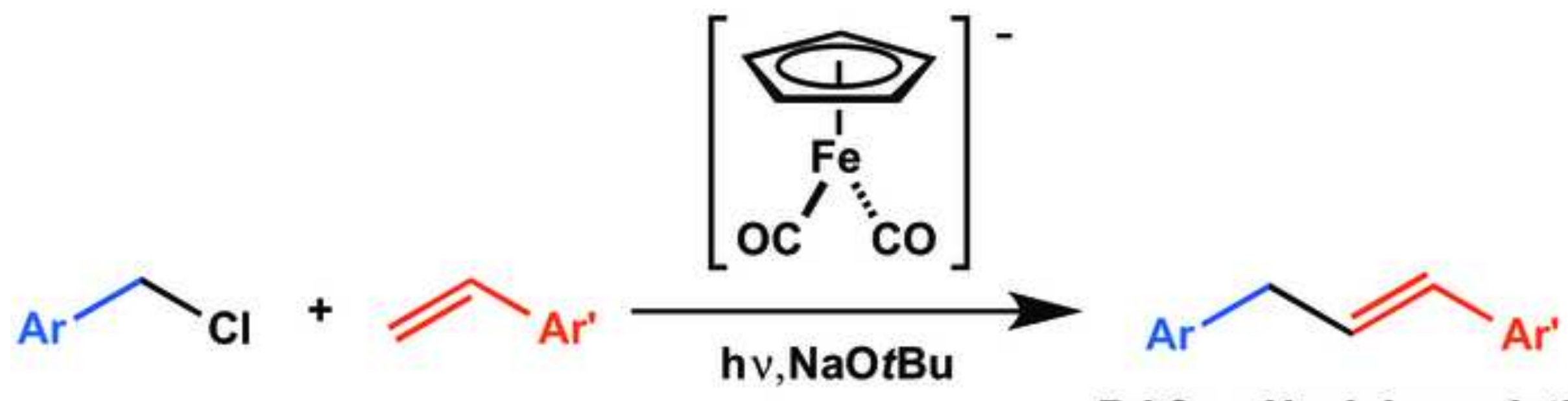

Pd-free Heck benzylation 